\title{
Border area tourism with problems and prospective: RF-Mongolia
}

\author{
Maria V. Kuklina ${ }^{1, *}$, Natalia E. Krasnoshtanova ${ }^{2}$, Andrey I. Trufanov ${ }^{1}$, Viktor $N$. \\ Bogdanov $^{2}$, and Sayana N. Erdinieva ${ }^{1}$ \\ ${ }^{1}$ Irkutsk National Research Technical University, 664074, Irkutsk, Russia \\ ${ }^{2}$ V B Sochava Institute of Geography SB RAS, 664033, Irkutsk, Ulan-Batorskaya str., Russia
}

\begin{abstract}
This article will explore the potential of the tourism sector in the districts of the Republic of Buryatia, Irkutsk region and Tyva, RF at the Russian-Mongolian border is based on a combination of a huge amount of diverse natural resources. The area in whole has rich water resources, including lakes, rivers, waterfalls and mineral springs, with well-preserved mountainous landscapes, in harmony with a centuries-old cultural and ethnic heritage of locals. Also, the Okinsky District has a unique location adjacent to the border between the Russian Federation and Mongolia. Despite its remoteness, the area might be considered as an attractive destination with great recreational prospects. However, several problems have been identified which impede severely active promotion of tourism. It is noteworthy that these are typical not only for the Okinsky district but common within many remote areas of the Russian Federation. Ways of solving the problems have been suggested to develop the tourism industry along with provision of environmental sustainability of the area and wellbeing of the local population.
\end{abstract}

\section{Introduction}

In the modern Russian economy, one can see that the importance of the service sector in the structure of total production is increasing steadily. Among others, tourism is one of the most promising service areas. This type of service is characterized by high growth rates and high consumer demand. Therefore, the development of tourism in the constituent entities of the Russian Federation in general and in the Republic of Buryatia in particular is one of the main vectors for development of the socio-economic sphere. At the same time, there are problems typical for most Russian regions in the eastern part of the country, caused by low development of infrastructure, which negatively impacts the prospects for tourism development. In this regard, the article is supposed to focus on the analysis of the current state of the tourism infrastructure of the study area, identifying vulnerabilities, formulating the main problems, outlining promising approaches and possible ways to solve them. It should be emphasized that with a balanced and comprehensive development of the tourism sector and its infrastructure, an increase in the standard of living of the local population is expected. Encountering challenges and solving urgent problems in the tourism sector offers

\footnotetext{
* Corresponding author: kuklina-kmv@yandex.ru
} 
new opportunities for the development of tourism as an important part of social life. The development of the tourism sector is directly related to the social sphere of the region, including the employment of locals, the quality of life of the population.

The increase in demand for tourism services within the country is associated with changes associated with the spread of SARS-CoV-2. Russian tourists are now traveling in RF due to restrictions related to the pertinent pandemic of COVID-19.

Rich recreational [1] and ethno-recreational [2] resources are considered to contribute to the development of tourism in the Baikal region. At the same time, limited transport accessibility, seasonality, lack of qualified personnel and hotels are the main factors hindering the development of tourism [3]. But the practice of some countries that have similar geographical conditions demonstrates that such regions, on the contrary, are experiencing an increase in tourism development (northern Finland, Yukon province, Canada, Alaska, USA). Infrastructure provision comes to the fore in such regions [4]. Thus, a significant role is assigned to determining the institutional and socio-cultural characteristics of tourism and its prospects within the framework of sustainable development of the territory.

At the same time, it is especially important to take into account the principles of sustainable development of remote and hard-to-reach territories. Sustainable tourism, as defined by the World Tourism Organization (WTO), is «tourism that takes full account of its current and future economic, social and environmental impacts, addressing the needs of visitors, the industry, the environment and host communities» [5].

As can be seen, the main aspects of the basic concept (society-economy-ecology) are also reflected in the definition.

Among Russian studies of the impact of tourism on the world economy, the work [6] might be marked as a significant one. It performed an in-depth analysis of approaches to the definition of the concept of "sustainable tourism". This concept is considered from the point of view of the total relations and phenomena occurring as a result of travel, from the point of view of temporary staying of citizens with a variety of purposes: those from health-improving and recreational to religious ones. This is especially relevant for this study, so that it takes into account socio-cultural and economic-geographical characteristics of the host destination.

\section{Materials and Methods}

The methodological basis of the research is the provisions of the systemic and situational approach and system analysis, also general scientific methods: ascent from abstract to particular issues, unity of logical and historical ones, analysis and synthesis. In the course of the study, we scrutinized data in the socio-economic state of the Okinsky district, as well as that in the tourism sector. Various sources were used to obtain the data, such as scientific publications, popular articles, tourist reviews, etc. Also at our disposal were our own field materials obtained in the course of collecting information in August 2020 in the Okinsky region, the Republic of Buryatia, RF.

The analysis and synthesis of the available records was performed thus, making it possible to structure those and thereby contribute to a deeper understanding of the topic. Various classifications and enumerations of data with numerous elements were also made. Based on an understanding of the current state of tourism in the study area, problems were identified that are directly related to the prospects for its future development. Therefore, the search for alternative solutions to the problems constitutes an important component of this article.

\section{Results}

This article presents characteristics of the Eastern Sayan terrain, specifically the Okinsky 
district, which now formally belongs to the Far East, RF [7].

This district is one of the westernmost entities of the Republic of Buryatia, RF, along with the neighboring Tunkinsky district. The area is located at a considerable distance from the regional capital, the city of Ulan-Ude. But at the same time, some advantage of the geographical location of the district is that it borders on Mongolia, the Republic of Tyva and the Irkutsk region [8]. This feature promoted formation of a new interesting international tourist destination Baikal (RF) - Khubsugul (Mongolia) - Tyva(RF).

Further development of this destination is supported by a number of positive factors, such as:

- High interest in Lake Baikal from international tourists, as well as Russian tourists are interested in Lake Khubsugul;

- Prospect of organising special tourist gate at the Russian-Mongolian border MondyKhanh;

- Positive dynamics of the development of ecological tourism infrastructure on Lake Khubsugul [9];

Russia has the longest state border in the world - more than 60 thousand km, borders with 16 states and is the \#1 in terms of the number of neighboring countries [10]. As one knows, the Republic of Buryatia touches Mongolia, that fact naturally has affected the history of both entities. The Okinsky District, in comparison with other neighboring Buryat districts, has the greatest length of the border and occupies one of the largest territories.

The territory of the district is characterized as an area with an extremely harsh climate, richness of mineral resources, remoteness and difficult access. The area of the terrain covers almost $26,594 \mathrm{~km} 2$. The terrain is a typical alpine relief, a mountainous landscape interspersed with plateau-like hills, with narrow valleys and many rivers and streams. Alpine meadows on the slopes of the ridges are used as distant pastures in summer. According to the census, the entire population of the district is 5470 people [11]. Thus, one can say that the geographical feature of the area has a special individual characteristic, and this gives certain advantages, such as a varied structure, picturesque landscapes, etc.

Obviously, the terrain key resource of active tourism is nature itself. The area is replete with natural monuments, untouched wildlife, as well as ethnic and national cultural heritage. Due to the richness of such resources, development of tourism in the Okinsky district is promising not only within general "nature" category but also for the other profiles, including:

- All-season active tourism;

- Mountaineering and skiing;

- Inpatient rest with stay in one place;

- Ecotourism;

- Medical and recreational ones;

- Religious one;

- Hunting tourism;

- Rural tourism;

- Excursions [12].

All these types and possibilities of tourism are brought together in the Okinsky district, thereby representing a promising foundation that makes sense to create concomitant tourist infrastructure. In this regard it is necessary to develop both each type of tourism separately, and to organize a comprehensive and interconnected harmonious structure of tourism in the region, just to bring a positive socio-economic impact. But it is especially important to note prospects for health tourism, which is popular among local residents and vacationers.

In 2020, a roadmap for development of tourism was elaborated at Buryatia administration, where, among the allocated tourist zones, and other things, the Baikal (RF)-Khubsugul (Mongolia) corridor was presented [13]. Since this route also passes through the Okinsky district, there may be new opportunities for development of tourism in the study area. 
The terrain of the region abounds with numerous mountain and water resources, which represent excellent landscape and recreational characteristics:

1. Munku-Sardyk is the highest point in Buryatia and the highest peak of the Eastern Sayan Mountains, $3491 \mathrm{~m}$ high. Climbing the mountain is one of the most popular routes in the Okinsky district;

2. Nukhen-Daban is a natural complex, which is a large hole in a mountain cliff, through which the old Okinsky trail goes: it had connected neighboring Okinsky and Tunkinsky districts in times before the highway was constructed.

3. The springs corresponding to Shumak River represent more than 110 sources various purposes, with temperatures from +10 to $+25 \mathrm{C}$. The thermal carbonic waters of Shumak with radon content are compared with the waters of "Tskhaltubo" (Pyatigorsk, Caucasus), Belokurikha (Altai) and Yamkun (Chita region) [14].

4. Zhoigan is famous for its numerous mineral springs and hot springs, which are used for healing many diseases. The Zhoygan Valley is located in the spurs of the Eastern Sayan at an altitude of 1685 meters above sea level, just west of the border between Tyva and Buryatia. The river Arak-Khem flows here, which takes its sources from the majestic Yenisei. The thermal waters of Zhoigan belong to bicarbonate calcium-sodium carbonate type; about 40 healing springs come out to the earth surface [15].

5. Khoyto-Gol. These are mineral thermal springs located around the Arshan stream which flows into the Khoyto-Gol river.

6. The Valley of Volcanoes (Khi-Gol pad, another name is Khikushka) is a unique natural monument in the mountains of the Eastern Sayan. Located in the wide valley of the Khikushka River, Oka Valley.

7. Dabatsky waterfall - a waterfall on the Dabata River, left tributary of the Tissa River, which flows into the Oka, in the Okinsky District. The waterfall is cascading, two-stage, located 2-3 km from the mouth of the Dabata river. It is formed on steep ledges of the Oka plateau. The maximum free fall height of water reaches approximately 85 meters. The total height of the waterfall is 1200 meters [16].

8. Lake Ilchir is famous with the fact that the Irkut River originates from that. Also, the lake is located at an altitude of 2000 meters above sea level.

9. Sailag waterfall (Small Zhom-Bolok) - 28 meters of free fall of water. Located 40 $\mathrm{km}$ far from Orlik. It is one of the favorite destinations visited by tourists. (see Fig. 1.). 


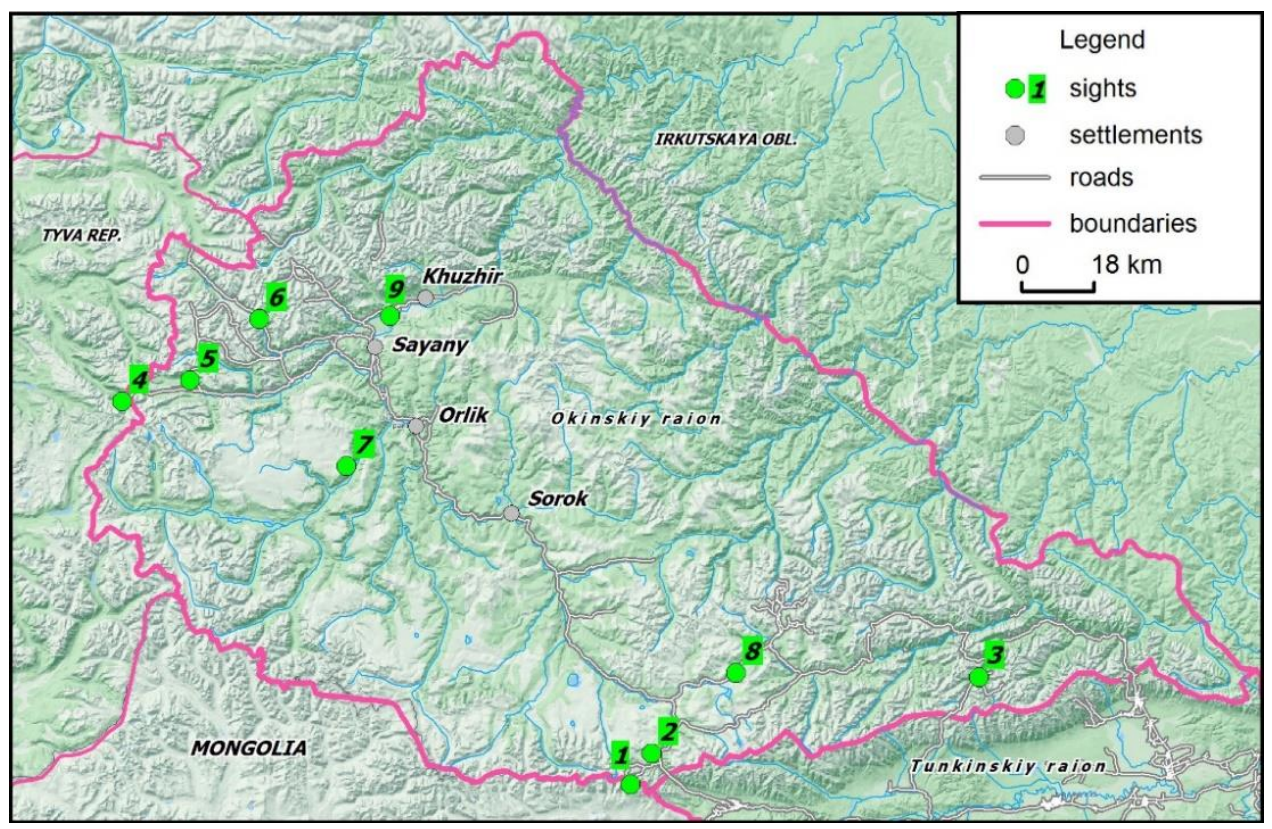

Fig. 1. Map of Okinsky district attractions.

\section{Discussion}

The prospects for the development of tourism in the Okinsky district are very high: the territory has numerous unique plots attractive for tourists which is undoubtedly a big plus. However, despite the numerous attractions of the Okinsky district (natural monuments, mineral and medicinal springs, etc.), tourism activity in the territory is not sufficiently developed.

According to official data of the administration, 4 collective accommodation facilities with a total of 99 beds are registered in the Okinsky district. One of them is well-known and popular Shumak tourist center with 48 places. According to these placements, total number of visitors to the area was 1,700 in 2020, due to restrictions on entering the area during peak seasons of SARS CoV-2 spread. Prior to the coronavirus pandemics the number of tourists had increased every year (see Fig. 2.). 


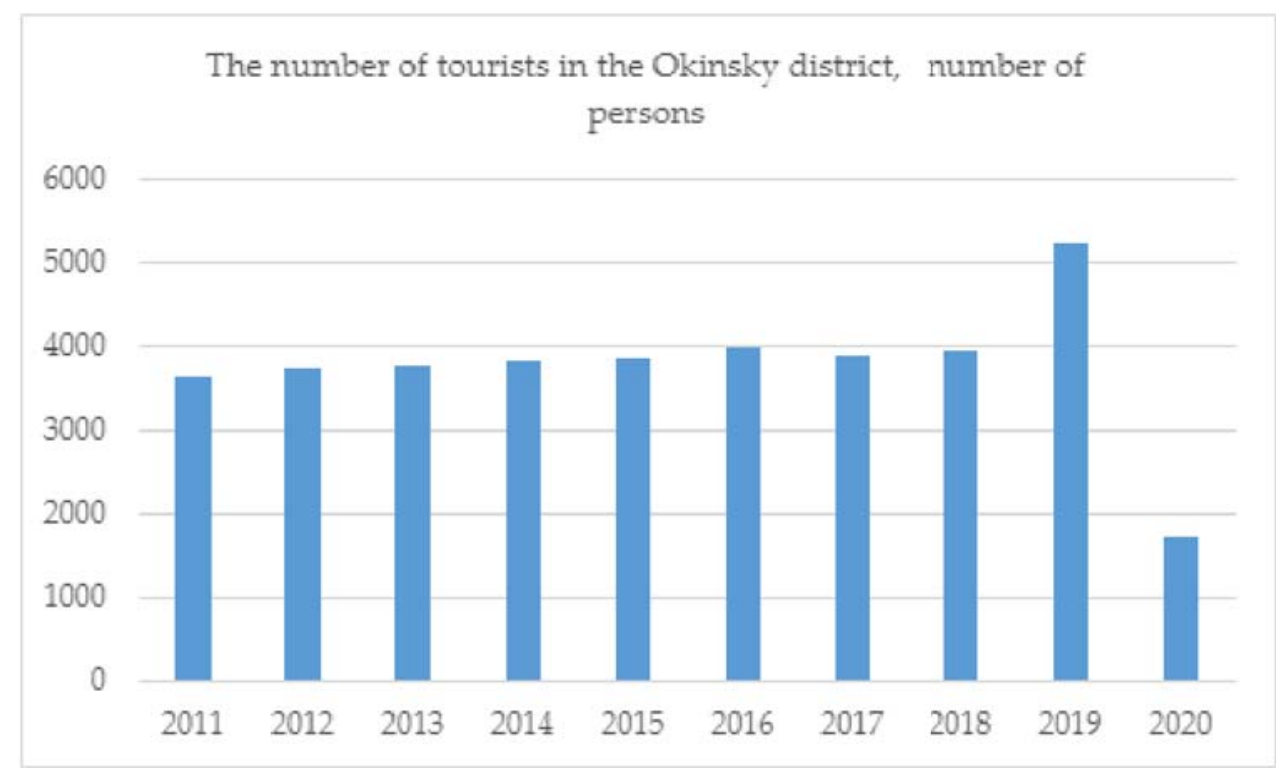

Fig. 2. The number of tourists in the Okinsky district by years.

Thus, counting the number of tourists in the area is taken according to the data of collective accommodation facilities. Individual ("wild") tourists are not counted.

The next key factors hinder development of tourism in the study area:

- Remoteness and difficult access;

- $\quad$ Poor infrastructure, including roads, communications, hotels, etc.;

- Lack of branding of the destination and few available information.

The development of cooperation between Russia and Mongolia in the field of tourism was marked by a bilateral agreement on visa-free tourist exchange in 2014. Such an agreement provides immense opportunities for promoting tourism, not only in the Okinsky region, but also in Russian Federation as a whole. But for successful functioning of the tourism destination, full-scale development of the entire infrastructure of the district is necessary. The borders are currently closed due to the restrictions associated with the pandemics. However, after the barriers are removed and taking into account the roadmap for tourism development in Buryatia, there is an excellent opportunity for the development of cross-border tourism with Mongolia.

Also, for the regions of Russia, a promising sphere is connected with medical and health tourism, which can also be developed in the Okinsky district. Concerning the quantity of mineral springs, the district is in first place in Buryatia. There are about 200 thermal springs there, such an abundance attracts many tourists who have various ailments and health problems. The active support of this type of tourism will give essential prospects for the development of the territory.

So, the most interesting from the point of view of tourist and recreational resources are: the Choigan (Zhoigan) mineral springs, located on the territory of traditional settlement of indigenous small peoples - Soyots and Tuvinians-Tozhins. Nevertheless, there is no tourist infrastructure near the springs, except for log cabins, a bathhouse and two toilets at each mineral bath. At the same time, it has become common to distinguish between groups of tourists and vacationers.

It is of some interest that locals call the residents of other neighboring settlements of the Okinsky District of the Republic of Buryatia and the Todzhinsky Kozhuun of the Republic of Tyva as "vacationers", as well as connected by relatives, friendships or other ties of 
residents of other Kozhuuns of Tyva and the districts of Buryatia, for whom the springs are the final and sometimes the only destination. Contrary "tourists" in this context are residents of other territories, for whom the springs are only one of the places on a long route associated with active tourism: rafting, kayaking, horse and hiking tours, mountain biking, on the way to lakes that attract amateurs of fishing.

Nearby, in the Okinsky district, there are the Khoytogol springs, where in the 1990s a resort complex was built it comprises five buildings, a dining room, a swimming pool and a pipe which is going from hot springs for heating one of the buildings. However, due to transfer of tax payments to the republican and federal budgets and the lack of competent management, the resort complex was closed. The remaining infrastructure is used for free by arriving tourists and local residents. In addition, schoolchildren from the neighboring village of Sayany use it as a children's sports and health camp [15].

The current state of recreation centers available for visiting tourists is characterized by a deficit or lack of information that tourists can find, who usually use the Internet to search, without access to certain local sources of information, such as acquaintances, for example. From the information available on websites about guest houses and tourist centers in the Republic of Buryatia, only 4 affordable housing might be found, which are located in the administrative center of the district, village of Orlik. The famous travel site Tripadvisor.ru advises the only available hotel in the popular Shumak area, but one should emphasize that there is practically no information about the destination. This factor greatly underestimates the possibilities of attracting tourists, because data on tourist places in the area are available only through such communication channels as viber and vk.com, which share information only to local residents.

\section{Conclusion}

Many eastern regions of Russia, due to their unique natural and cultural potential, as well as the ever-increasing interest from domestic tourists as a new uncovered destination, has every reason for the development of tourism.

Thus, the Okinsky District of the Republic of Buryatia has great potential in terms of tourism development. The possibility of active development and promotion of this area of development is due to the unique attractions that cannot be found elsewhere.

The study area is rich in balneological and recreational resources. The possibilities of using mineral springs for the treatment of a wide range of diseases, combined with an attractive natural landscape, make it possible to consider this tourist destination as the most promising one. To provide tourists with high quality services, a serious contribution is needed from all the main components of the infrastructure of the subject industry, taking into account the territorial specifics, with the subsequent formulation of practical proposals for the development of tourism in this territory. It is of value to note that with a balanced and comprehensive development of the tourism sector and its infrastructure, an increase in the standard of living of the local population might be expected.

The cultural and ethnic heritage, which the inhabitants of the area have carefully preserved and still respect, has helped to protect the nature of the Oka River and preserve it in an intact and unspoiled state. The unique location gives a chance for the development of international border area tourism. All this influenced the current state of the area, which has every chance of becoming a popular tourism destination. However, the problems that often arise in the remote territories of the Russian Federation, characterized by poor infrastructure, do not make it possible to consistently improve the tourism sector. Being overcome those will increase the chances of the Okinsky district to become one more entity with an attractive tourist infrastructure and, moreover, will improve the state of the region as a whole, which will undoubtedly affect the life of the local population. 


\section{Acknowledgments}

The study was funded by RFBR and MECSS, project number 20-57-44002 "Interdisciplinary network platform for modeling socio-economic and environmental processes in the crossborder territories of the Russian Federation and Mongolia with limited transport accessibility".

\section{References}

1. A.K. Tulokhonov, Baikal: nature and people: An encyclopedic reference book (2009)

2. O.V. Evstrop'eva, Etnorekreatsionnyy potentsialnogo Baykalskogo regiona 1, 127-135 (2013)

3. A.D. Abalakov, N.S. Pankeeva, Features of tourism development during the global economic crisis 3, 111-117 (2011)

4. A. Lorentzen, The development of the periphery in the experience economy, 16-29 (2012)

5. UNITED

NATIONS. Sustainable

tourism, https://sustainabledevelopment.un.org/topics/sustainabletourism

6. O.V. Pirogova, A.Yu. Pirogova, International Journal of Applied and Fundamental Research (2017)

7. A.B. Imetkhenov, Atlas of the Republic of Buryatia (2000)

8. E.N. Bochkarev, Mountain ecosystems of Southern Siberia: Study, protection and rational use of natural resources, Second Interregional scientific and practical conference dedicated to the 10th anniversary of the organization (2015)

9. Amarjargal and Purefdzaa, Baikal Project (Young Scientist 29133 2016)

10. O.B. Angapova, Bulletin of BSU 2, 76-79 (2014)

11. A.I. Rossihin Tourism as a factor of sustainable development of mountain territories, Collection of materials of the I International scientific-practical conference (2018)

12. V. Pochaev, N. Atanov, G.J. Shubenkov and D.D. Tsyrenov, Vestnik BGU 1, 29-39 (2020)

13. The Ministry of Tourism of The Republic Of Buryatia, https://bgtrk.ru/news/society/196017/

14. Okinsky district. Official portal of the state authorities of the Republic of Buryatia, http://egov-buryatia.ru/index.php?id=467

15. V.V. Kuklina, Cultural and Humanitarian geographies 1(2), 180-190 (2012)

16. Dangaa Enkhtaivan and O. V. Evstropyeva, Modern problems of service and tourism 4(9), 37-43 (2015) 